\title{
Hepatitis B awareness and education: A failing grade
}

\author{
Kelly W Burak MD FRCPC MSc(Epid), Carla S Coffin MD FRCPC MSc, \\ Robert P Myers MD FRCPC MSC(Epid)
}

\begin{abstract}
$\mathrm{A}^{\mathrm{p}}$
pproximately 2 billion people worldwide have been exposed to the hepatitis B virus (HBV) and approximately 350 million are chronically infected (1). Although Canada is considered to have a low rate of hepatitis B surface antigen ( $\mathrm{HBs} A g$ ) positivity (Figure 1), immigration from endemic countries still leads to a significant burden of disease in our country. The true prevalence of chronic HBV in Canada is unknown, but the Public Health Agency of Canada has estimated that there are approximately 180,000 chronic carriers, representing $0.7 \%$ to $0.9 \%$ of the Canadian population (2). Leber and Sherman (3) factored in the impact of immigration to obtain a more accurate reflection of the burden of HBV in our country. Canada accepted nearly four million immigrants between 1981 and 2006, of which $90 \%$ came from countries where HBV is of moderate to high endemicity (prevalence greater than 2\% [Figure 1]). Based on an estimate that $5.2 \%$ of immigrants (ie, more than 200,000 individuals) were chronic HBV carriers during this 25-year time period, Leber and Sherman projected that the true seroprevalence of HBV in Canada is closer to $1.26 \%$. Unless we identify and appropriately treat these patients, we can expect an increasing burden to our health care system due to new cases of cirrhosis, liver failure and hepatocellular
\end{abstract}

carcinoma (HCC). In fact, a recent report (4) found that HBV followed only hepatitis $\mathrm{C}$ as the leading cause of years of life lost due to premature mortality from an infectious disease in Ontario. The Ontario Burden of Infectious Disease study (4) estimated that 346 deaths per year are directly attributable to chronic HBV infection in Ontario. This is a sobering statistic considering the availability of well-tolerated and highly effective antiviral drugs for HBV infection.

Numerous barriers exist that hinder chronic HBV patients from accessing appropriate screening and treatment (5). Patients often confront language barriers, have limited knowledge of the risks of HBV transmission and the need for vaccination of family members, and they may not grasp the severe consequences of chronic HBV including cirrhosis and HCC. Furthermore, many patients worry about the stigmatization that may occur following identification as a carrier of a chronic infectious disease (5). In the present issue of The Canadian Journal of Gastroenterology, Sam et al (6) (pages 127-134) address yet another barrier to appropriate HBV management - specifically, deficiencies in the knowledge base regarding HBV by Canada's future family practitioners.

The reported state of HBV-related knowledge among Canadian family medicine residents is concerning on many levels. Although

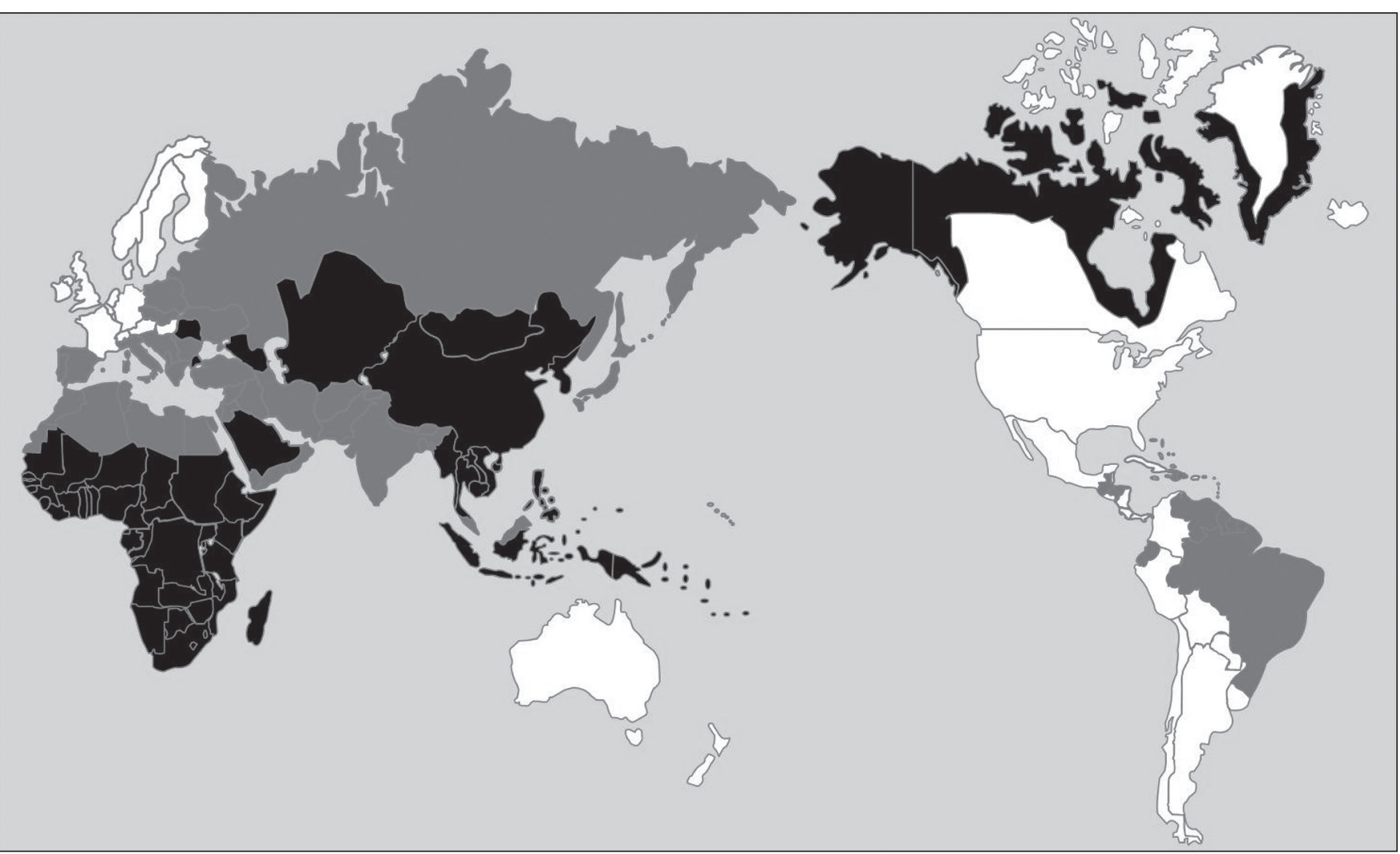

Figure 1) Worldwide rates of chronic hepatitis B virus surface antigen positivity. Black greater than $8 \%$, grey $2 \%$ to $8 \%$, white less than $2 \%$. Based on data from the World Health Organization, 2002 (8)

Liver Unit, Division of Gastroenterology, Department of Medicine, University of Calgary, Calgary, Alberta

Correspondence: Dr Kelly W Burak, Liver Unit, Division of Gastroenterology, Department of Medicine, University of Calgary, Room 6D35 Teaching,

Research and Wellness Building, 3350 Hospital Drive Northwest, Calgary, Alberta T2N 4Z6. Telephone 403-592-5049, fax 403-592-5090,

e-mail kwburak@ucalgary.ca

Received and accepted for publication February 8, 2011 
these trainees correctly interpreted HBV serology, approximately one-quarter to one-third did not recognize the necessity of screening patients from endemic areas and those exhibiting high-risk behaviours (eg, injection drug users and men who have sex with men). First and foremost, chronic HBV carriers must be identified by their family physician before appropriate counselling and consideration of therapy can even occur. It is paramount that HBV is 'put on the map', so to speak, and that any patient from a country of moderate to high endemicity (illustrated in grey or black in Figure 1) should be tested for HBsAg and anti-HBs antibodies to investigate chronic infection or immunity. Second, there appears to be confusion regarding the need for and timing of referral to a specialist. For example, most of the surveyed residents would refer a young female in the immune-tolerant phase of infection, but less than $60 \%$ of respondents would refer a patient with $\mathrm{HBeAg}$-negative chronic HBV with active viral replication and thrombocytopenia. The latter patient probably has cirrhosis and should likely receive antiviral therapy and surveillance for HCC. Although the study's authors considered referral of an immune-tolerant patient as inappropriate because therapy is not typically offered in this situation, we would argue with this conclusion. In our opinion, evaluation of such a patient by physicians experienced in the management of chronic HBV would facilitate appropriate counselling regarding several issues including the need for vaccination of family members and sexual contacts, the risks of vertical transmission and the potential role of antiviral therapy to reduce this risk in future pregnancies, the timing of HCC screenings, and the need for ongoing monitoring of alanine aminotransferase and HBV DNA levels to guide the initiation of antiviral therapy at a more appropriate time point in the future.

A striking finding of the study by Sam et al (6) was that only 3\% of respondents identified the high likelihood of cirrhosis in a chronic HBV carrier with a platelet count of $125 \times 10^{9} / \mathrm{L}$. Thrombocytopenia is a specific marker of cirrhosis in patients with chronic liver disease (7). We triage patients who are referred to our Viral Hepatitis Clinic

\section{REFERENCES}

1. World Health Organization. Hepatitis B fact sheet, revised August 2008. < http://www.who.int/mediacentre/factsheets/fs204/en/ index.html $>$ (Accessed on February 1, 2011).

2. Public Health Agency of Canada, Hepatitis B - Get the Facts. $<$ http://www.phac-aspc.gc.ca/hcai-iamss/bbp-pts/hepatitis/hep_b-eng. php>. (Accessed on February 1, 2011).

3. Leber M, Sherman M. Estimation of immigration related chronic hepatitis B infection and hepatocellular carcinoma development in Canada from 1981-2006. Can J Gastroenterol 2009;23(Suppl A):A22.

4. Ontario Burden of Infectious Disease Study (ONBOIDS), December 2010. <http://www.oahpp.ca/resources/documents/reports/ onboid/ONBOIDS_EXECUTIVE_SUMMARY.pdf> (Accessed on February 1, 2011). in Calgary (Alberta) with thrombocytopenia as in need of expedited priority for consultation. Family physicians need to be reminded that it is important to rule out chronic liver disease in thrombocytopenic patients using liver biochemistry and, if appropriate, screening tests for common causes of chronic liver disease and an assessment of the severity of liver fibrosis (liver biopsy or FibroScan) before a patient is labelled as having idiopathic thrombocytopenia. The survey also illustrates the need to better educate primary care physicians about the appropriate management of patients with cirrhosis. Cirrhotic patients not only require screening for esophageal varices and HCC, but also counselling regarding the risks of nonsteroidal anti-inflammatory drugs - which may cause gastrointestinal bleeding and hepatorenal syndrome - and narcotics, which carry a risk of encephalopathy in this patient population. It continues to be a common misconception that patients with cirrhosis should avoid acetaminophen, whereas in truth, only those actively abusing alcohol are at increased risk of hepatotoxicity following therapeutic doses of this medication.

The study by Sam et al (6) has some limitations including the low survey response rate (less than 15\%) and the fact that no residents from the University of British Columbia responded, given the large population of HBV carriers in the Vancouver area. Overall, however, we applaud the efforts of Sam et al for bringing to light the gaps in knowledge of Canada's family medicine trainees with regard to identifying and managing patients with chronic HBV and cirrhosis. This study should serve as a wake-up call to members of The Canadian Association for the Study of the Liver, the Canadian Association of Gastroenterology, the Canadian Liver Foundation and all of us involved in undergraduate, postgraduate and continuing medical education. We must commit time and resources to improving the education of our front-line physicians in understanding complex liver diseases, including HBV, so that we can optimize the diagnosis and management of this important and often under-recognized patient population.

5. Leung W, Heathcote EJ. Unmet needs of chronic hepatitis B. US Gastroenterol Hepatol Rev 2008;4:24-7. <www.touchgroupplc. com/pdf/3234/heathcote.pdf > (Accessed on February 1, 2011).

6. Sam JJ, Heathcote EJ, Wong DKH, WoosterDL, Shah H. Hepatitis B learning needs assessment of family medicine trainees in Canada: Results of a nationwide survey. Can J Gastroenterol 2011;25:127-34.

7. Lu SN, Wang JH, Liu SL, et al. Thrombocytopenia as a surrogate for cirrhosis and a marker for the identification of patients at high-risk for hepatocellular carcinoma. Cancer 2006;107:2212-22.

8. Hepatitis B. World Health Organization 2002. <http://www.who. int/csr/disease/hepatitis/HepatitisB_whocdscsrlyo2002_2.pdf> (Accessed on February 1, 2011). 


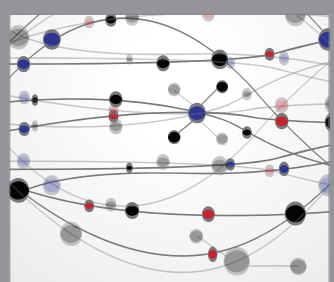

The Scientific World Journal
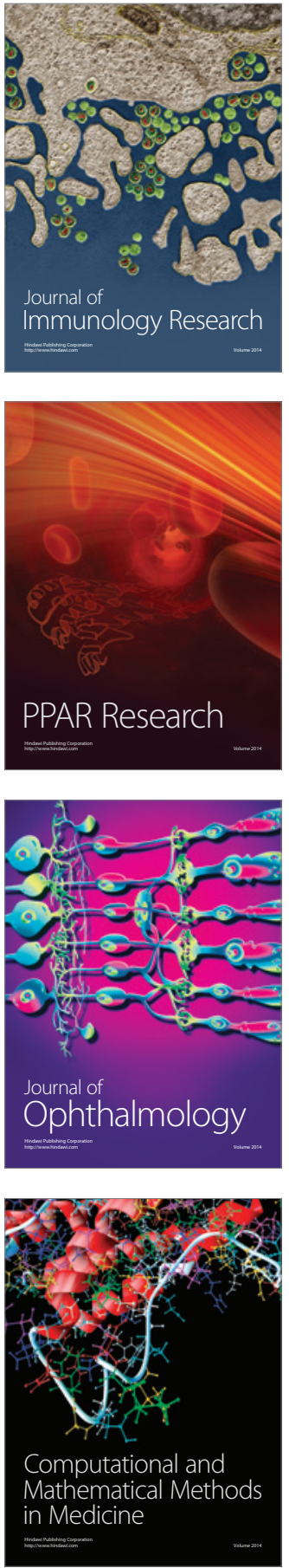

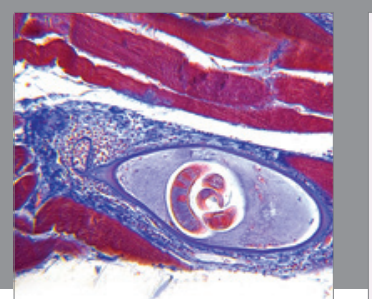

Gastroenterology Research and Practice

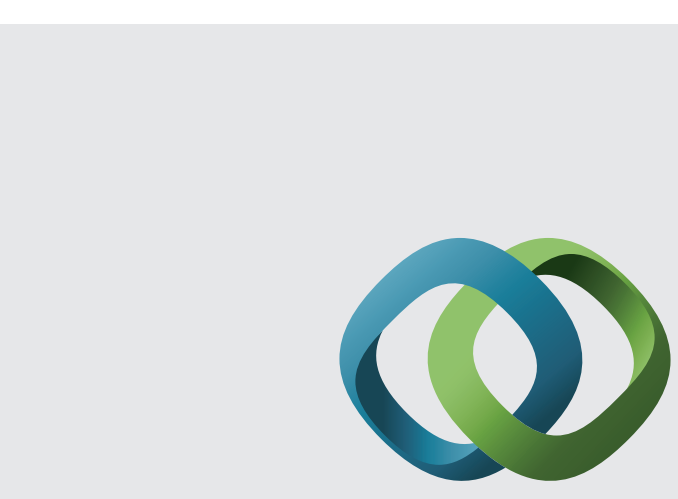

\section{Hindawi}

Submit your manuscripts at

http://www.hindawi.com
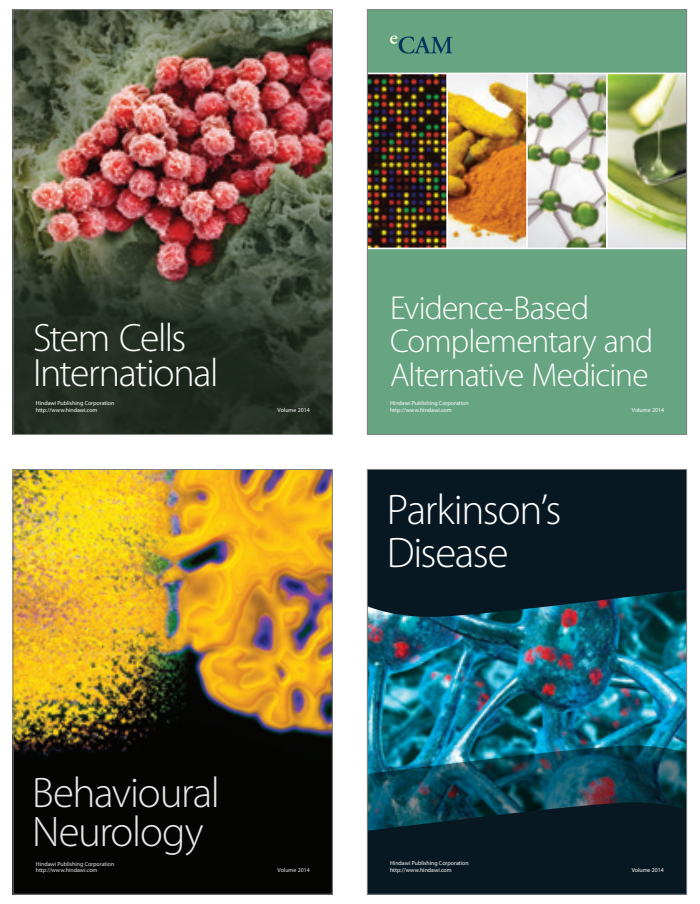
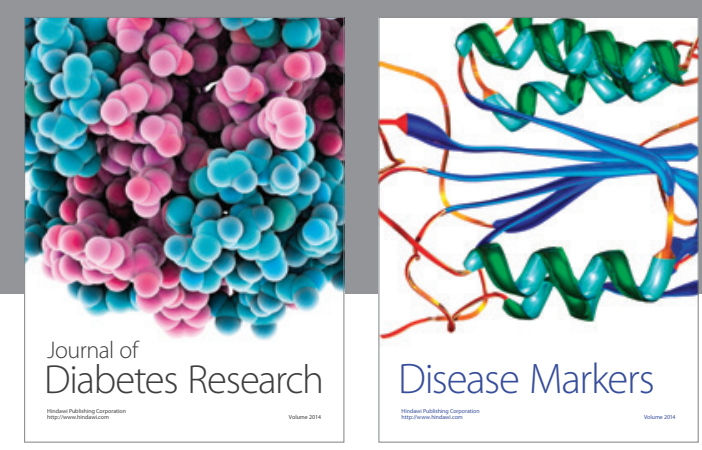

Disease Markers
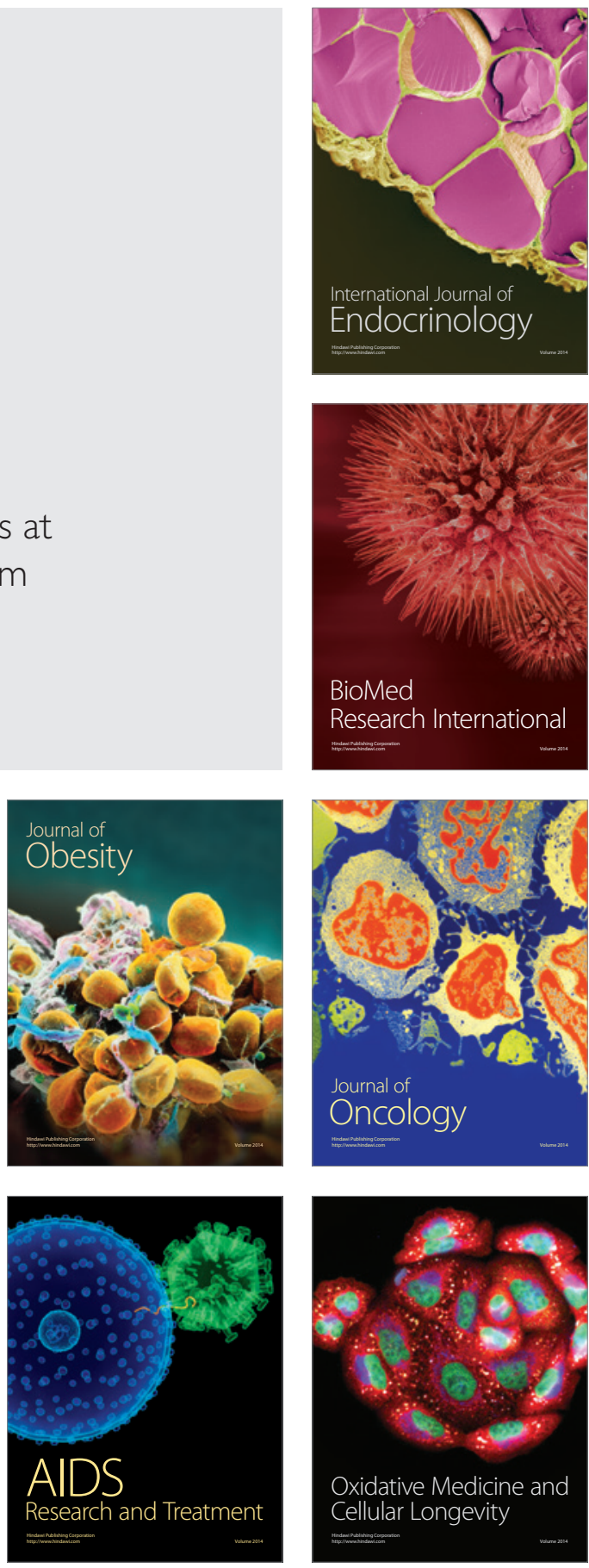